\title{
Regulation of anti-apoptotic signaling by Kruppel-like factors 4 and 5 mediates lapatinib resistance in breast cancer
}

\author{
MK Farrugia ${ }^{1,2}$, SB Sharma ${ }^{1,2}$, C-C Lin ${ }^{1,3}$, SL McLaughlin ${ }^{3}$, DB Vanderbilt ${ }^{1,2}$, AG Ammer $^{3}$, MA Salkeni ${ }^{3,4}$, P Stoilov ${ }^{1,2,3}$, YM Agazie ${ }^{1,2,3}$, \\ CJ Creighton ${ }^{5}$ and JM Ruppert ${ }^{\star, 1,2,3}$
}

The Kruppel-like transcription factors (KLFs) 4 and 5 (KLF4/5) are coexpressed in mouse embryonic stem cells, where they function redundantly to maintain pluripotency. In mammary carcinoma, KLF4/5 can each impact the malignant phenotype, but potential linkages to drug resistance remain unclear. In primary human breast cancers, we observed a positive correlation between KLF4/5 transcript abundance, particularly in the human epidermal growth factor receptor 2 (HER2)-enriched subtype. Furthermore, KLF4/5 protein was rapidly upregulated in human breast cancer cells following treatment with the HER2/epidermal growth factor receptor inhibitor, lapatinib. In addition, we observed a positive correlation between these factors in the primary tumors of genetically engineered mouse models (GEMMs). In particular, the levels of both factors were enriched in the basal-like tumors of the C3(1) TAg (SV40 large T antigen transgenic mice under control of the C3(1)/prostatein promoter) GEMM. Using tumor cells derived from this model as well as human breast cancer cells, suppression of KLF4 and/or KLF5 sensitized HER2-overexpressing cells to lapatinib. Indicating cooperativity, greater effects were observed when both genes were depleted. KLF4/5-deficient cells had reduced basal mRNA and protein levels of the anti-apoptotic factors myeloid cell leukemia 1 (MCL1) and B-cell lymphoma-extra large (BCL-XL). Moreover, MCL1 was upregulated by lapatinib in a KLF4/5-dependent manner, and enforced expression of MCL1 in KLF4/5-deficient cells restored drug resistance. In addition, combined suppression of KLF4/5 in cultured tumor cells additively inhibited anchorage-independent growth, resistance to anoikis and tumor formation in immunocompromised mice. Consistent with their cooperative role in drug resistance and other malignant properties, KLF4/5 levels selectively stratified human HER2enriched breast cancer by distant metastasis-free survival. These results identify KLF4 and KLF5 as cooperating protumorigenic factors and critical participants in resistance to lapatinib, furthering the rationale for combining anti-MCL1/BCL-XL inhibitors with conventional HER2-targeted therapies.

Cell Death and Disease (2015) 6, e1699; doi:10.1038/cddis.2015.65; published online 19 March 2015

In mouse embryonic stem (ES) cells, pluripotency is maintained by the redundant function of three Kruppel-like transcription factors, KLF2, KLF4 and KLF5. ${ }^{1}$ Furthermore, as determined by chromatin immunoprecipitation combined with high-throughput sequence analysis (ChIP-seq), KLF4 and KLF5 (KLF4/5) have both overlapping and distinct target genes. $^{2}$ Depletion of KIf4 or KIf5 in the anterior eye elicits similar developmental phenotypes, whereas in other tissues they exert opposing influences. ${ }^{3-5}$ For example, KLF4/5 differentially affect the expression of several cell cycle regulatory proteins, such as CCND1, CCNB1 and p2 $1^{\text {Waf1/Cip } 1.3}$ In adult tissues, KLF4 and/or KLF5 are induced by a variety of stress stimuli and can promote cell survival in diverse contexts. ${ }^{3,6-9}$

In breast cancer, KLF4/5 protein levels or mRNA abundance are elevated in aggressive primary tumors. ${ }^{10-13}$ Consistent with these results, promoter demethylation of $K L F 4$ or KLF5 in breast tumors is associated with an unfavorable clinical course. ${ }^{14}$ Individually, both KLF4/5 exert oncogenic functions in experimental models of cancer such as cellular transformation, migration, invasion and xenograft formation. ${ }^{15-19}$ Although signaling mechanisms remain to be elucidated, KLF4 directly regulates the transcription of microRNA-206 (miR-206) to promote tumor cell survival and tumor initiation in

\footnotetext{
${ }^{1}$ Department of Biochemistry, West Virginia University Health Sciences Center, Morgantown, WV 26506, USA; ${ }^{2}$ Program in Cancer Cell Biology, West Virginia University, Morgantown, WV 26506, USA; ${ }^{3}$ The Mary Babb Randolph Cancer Center, West Virginia University, Morgantown, WV 26506, USA; ${ }^{4}$ Department of Medicine, West Virginia University, Morgantown, WV 26506, USA and ${ }^{5}$ Department of Medicine and Dan L Duncan Cancer Center, Division of Biostatistics, Baylor College of Medicine, Houston, TX 77030, USA

${ }^{*}$ Corresponding author: JM Ruppert, Department of Biochemistry, West Virginia University Health Sciences Center, 1 Medical Center Drive, PO Box 9142 , Room 212 Biomedical Research, Morgantown, WV 26506, USA. Tel: +1 304293 5246; Fax: +1 304293 4667; E-mail: mruppert@hsc.wvu.edu

Abbreviations: BCL2, B-cell lymphoma 2; BCL-XL, B-cell lymphoma-extra large; C3(1) Tag, SV40 large T antigen transgenic mice under control of the C3(1)/prostatein promoter; ChIP-seq, chromatin immunoprecipitation combined with high-throughput sequence; Cl, confidence interval; DAPI, 4',6-diamidino-2-phenylindole; DFS, diseasefree survival; DMFS, distant metastasis-free survival; ES cells, embryonic stem cells; EGFR, epidermal growth factor receptor; GEMM, genetically engineered mouse model; HER2, human epidermal growth factor receptor 2; KLF, Kruppel-like factor; KLF4/5, KLF4 and KLF5; MAPK, mitogen-activated protein kinase; miR-206, microRNA-206; MMI, mitochondrial membrane integrity; MMTV, mouse mammary tumor virus promoter; MCL1, myeloid cell leukemia 1; PI3K, phosphatidylinositide 3kinase; qRT-PCR, quantitative reverse transcription and polymerase chain reaction; RTK, receptor tyrosine kinase; TCGA, The Cancer Genome Atlas; TNBC, triplenegative breast cancer

Received 12.11.14; revised 10.2.15; accepted 12.2.15; Edited by J Chipuk
} 
athymic mice (manuscript submitted). ${ }^{18,20}$ Although independently KLF4/5 have important roles in breast cancer, the relationship between the two genes in this disease remains understudied.

We observed a positive correlation of $K L F 4 / 5$ expression in the human epidermal growth factor receptor 2 (HER2)enriched breast cancer subtype. In addition, in these patients the median expression of both $K L F 4 / 5$ significantly stratified the distant metastasis-free survival (DMFS). Clinically approved HER2-targeted therapies such as lapatinib and trastuzumab (Herceptin) have significantly improved the disease-free survival (DFS) of patients with HER2-amplified breast cancers. $^{21,22}$ However, eventual resistance to these therapies is observed in the majority of cases, representing a major obstacle to long-term cures. ${ }^{23-26}$

Several mechanisms of resistance have been described, often involving sustained signaling through dimerization with other receptor tyrosine kinases (RTKs) or activating mutations in downstream effectors, namely RAS pathway components. ${ }^{27-32}$ Although numerous pathways to resistance have been characterized, it is unclear which of these mechanisms predominate in patients and how they are specifically regulated.

Interestingly, neutralization of apoptotic signaling contributes to anti-HER2 therapeutic failure. ${ }^{33-35}$ For example, phosphorylation of $\mathrm{BAD}$ or overexpression of B-cell lymphoma-extra large (BCL$\mathrm{XL}$ ) reduces the efficacy of these drugs. One such drug is lapatinib, a HER2/epidermal growth factor receptor (EGFR) inhibitor that has activity not only in the HER2+ cancers of patients, but also shows efficacy in combination with other agents in basal-like breast cancer models. ${ }^{36,37}$ We observed that lapatinib treatment of HER2-amplified tumor cells resulted in the rapid induction of KLF4/5. Subsequent experiments demonstrated a novel role for the endogenous KLFs in the regulation of antiapoptotic factors. As shown by shRNA studies, in the presence of lapatinib KLF4/5 coregulated the expression of myeloid leukemia cell 1 (MCL1) and cooperated to confer lapatinib resistance. Even in the absence of drug treatment, the endogenous KLFs were critical for maintaining basal levels of the anti-apoptotic factors MCL1 and BCL-XL, and collaboratively promoted the malignant phenotype. KLF4/5 were positively correlated with MCL1 in primary breast tumors, and enforced expression of MCL1 was sufficient to rescue the lapatinib sensitivity of KLF4/5-deficient cells. These results identify $\mathrm{KLF} 4 / 5$ as inducible regulators of lapatinib resistance through mediation of anti-apoptotic signaling.

\section{Results}

KIf4 and KIf5 are differentially expressed and positively correlated in genetically engineered mouse models (GEMMs) of breast cancer. To better understand how the expression of these two KLFs are altered during mammary tumorigenesis, we analyzed the levels of Klf4/5 in GEMMs of breast cancer. ${ }^{38}$ As a complement to human tumor analysis, individual GEMMs offer a genetically homogenous background where tumors arise in the context of specific genetic alterations.

Of 108 tumors in the microarray data set, we analyzed 58 tumor samples across 9 different GEMMs. ${ }^{38}$ We omitted models that had very low abundance of Klf4/5, including p53deficient models and models on the BALB/c background. We also omitted samples that did not cluster into an intrinsic subtype (14 tumor samples), and we excluded the mesenchymal subgroup tumors because of heterogeneity in GEMM of origin (five tumors) (Figure 1a). Unlike for KIf5, KIf4 expression as determined by microarray analysis varied substantially across the mouse model tumors, with higher expression in mice transgenic for the coding region of SV40 large $\mathrm{T}$ antigen driven by the $\mathrm{C} 3(1)$ /prostatein promoter (i.e., C3(1) TAg) than in mouse mammary tumor virus promoter (MMTV)-Neu tumors. Collectively, Klf4 levels were significantly lower in GEMMs that generated predominantly luminal tumors relative to tumors with basal characteristics $(P<0.0001)$.

Interestingly, the expression of KIf4/5 were positively correlated in the 58 GEMM tumors $(R=0.5658, P<0.0001$; Figure $1 \mathrm{~b}$, upper panel). Among the tumor subgroups, the strongest correlation was observed in basal tumors ( $R=0.8242, P=0.0005$; Figure $1 \mathrm{~b}$, lower panel). Significant correlations were also present in the luminal tumors (data not shown). Indicating specificity, Klf4 or KIf5 did not correlate or trend toward a correlation with another KLF, Klf2 (data not shown). ${ }^{1}$

To more accurately quantitate gene expression, we isolated spontaneous tumors from the C3(1) TAg and MMTV-Neu models and measured mRNA levels by quantitative reverse transcription and polymerase chain reaction (qRT-PCR; Figure 1c, left panel). In the C3(1) TAg tumors, Klf4/5 abundance averaged 2.6- and 3.5-fold higher than normal breast, respectively. In contrast, MMTV-Neu tumors showed markedly reduced levels of both factors. The two models differed in average abundance by 158- and 26-fold for Klf4/5, respectively $(P<0.0001)$. In these tumors, KIf4/5 mRNA correlated strongly (Figure 1c, right panel; $R=0.8273$, $P=0.0024)$. Consistent with animal model data, the protein expression of KLF4/5 in 10 different human breast cancer cell lines was positively correlated $(R=0.8847, P=0.0007$; Figure 1d). For KLF5, the smaller fragment of approximately $48 \mathrm{kDa}$ present in the luminal breast cancer cell lines may be attributed to estrogen-dependent processing. ${ }^{39}$

Figure 1 Klf4 and Klf5 are differentially expressed and positively correlated in GEMMs of breast cancer. (a) Microarray analysis of Klf4/5 levels across GEMMs of breast cancer. Data for 58 mammary tumors from the Gene Expression Omnibus (GSE3165) were organized by GEMM and molecular subtype. Expression values were normalized to whole mouse RNA (bars, S.D.). Klf4 levels in luminal and non-luminal tumors were compared via one-way ANOVA using Dunnet's post test $(P<0.0001)$. (b) Spearman's correlation was performed for the samples in panel a. (c) qRT-PCR analysis of total RNA isolated from tumors of MMTV-Neu or C3(1) TAg transgenic mice (left panel). Normal mammary tissue from FVB/N mice was analyzed similarly (NL breast, $N=3$ ). Tumor mean expression is depicted relative to the mean for normal tissue (bars, $\mathrm{S}$.E.). The overall mean tumor expression of Klf4 and KIf5 was compared between GEMMs using a two-tailed $t$-test (for each gene, $P<0.0001$ ). The log 2 transformed data were assessed by Spearman's correlation (right panel). (d) Western blot analysis of KLF4/5 levels in whole-cell lysate of 10 different breast cancer cell lines. KLF expression was determined using ImageJ and normalized to $\beta$-actin. The expression values were assessed by Spearman's correlation (right panel) 
Prognostic significance of $K L F 4$ and $K L F 5$ in HER2enriched breast cancer. As KLF4/5 were correlated in breast cancer models, we next examined whether this relationship is informative to patient outcome. We performed Kaplan-Meier analyses of DMFS using a previously described compendium of gene expression profiling data sets representing 1065 cases. ${ }^{40}$ Median expression levels were used to define the groups. We excluded normal breastlike tumors from analysis because these samples often contain high amounts of contaminating normal cells. ${ }^{41}$

Across all tumors, KLF4 levels showed no significant relationship with DMFS (Figure 2a). In contrast, a

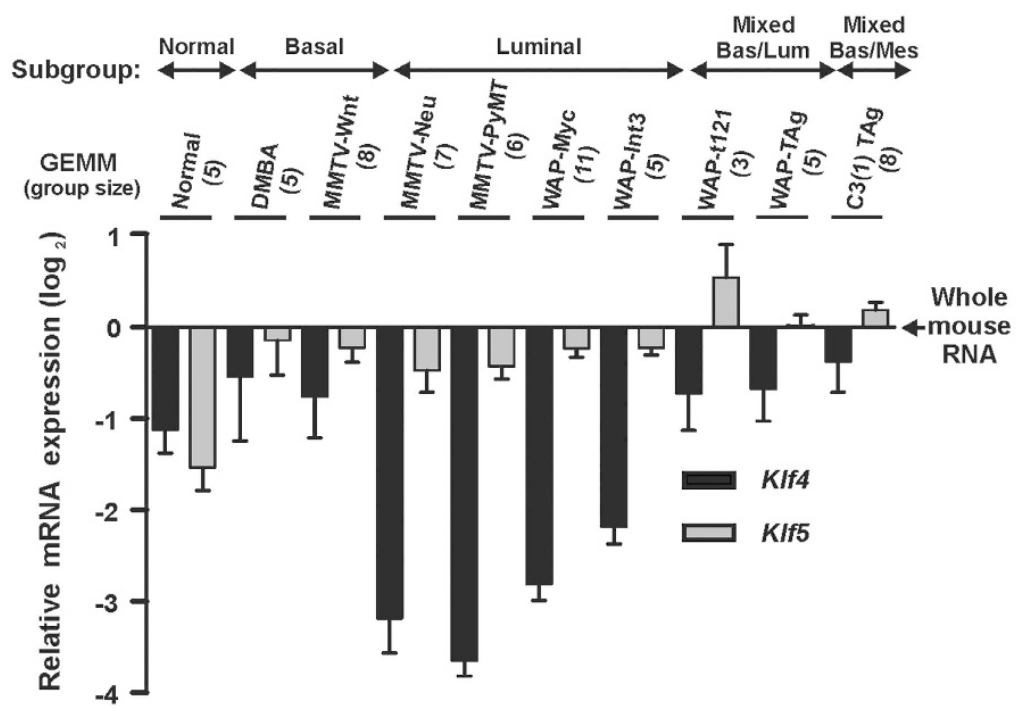

b

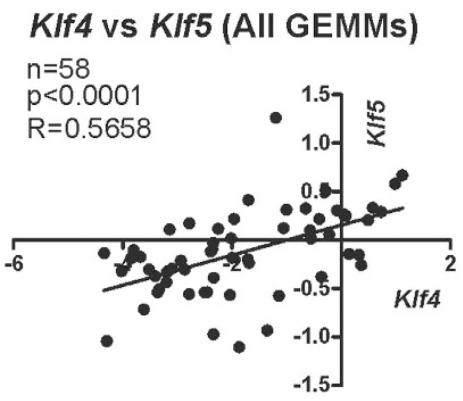

KIf4 vs KIf5 (Basal GEMMs)

$\mathrm{n}=13$

$\mathrm{p}=0.0005$

$\mathrm{R}=0.8242$

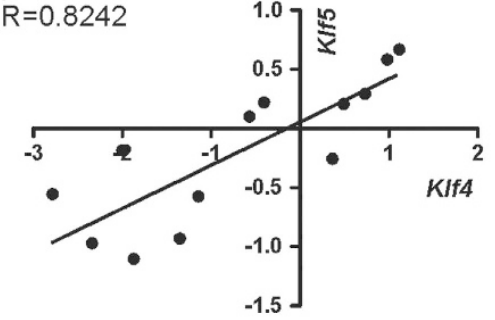

C
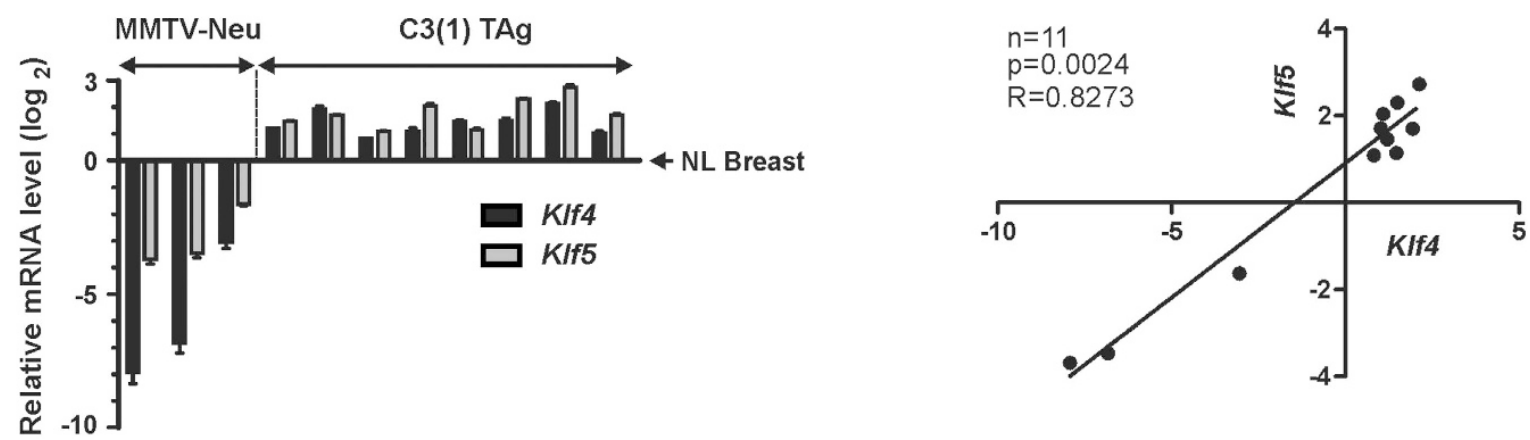

d
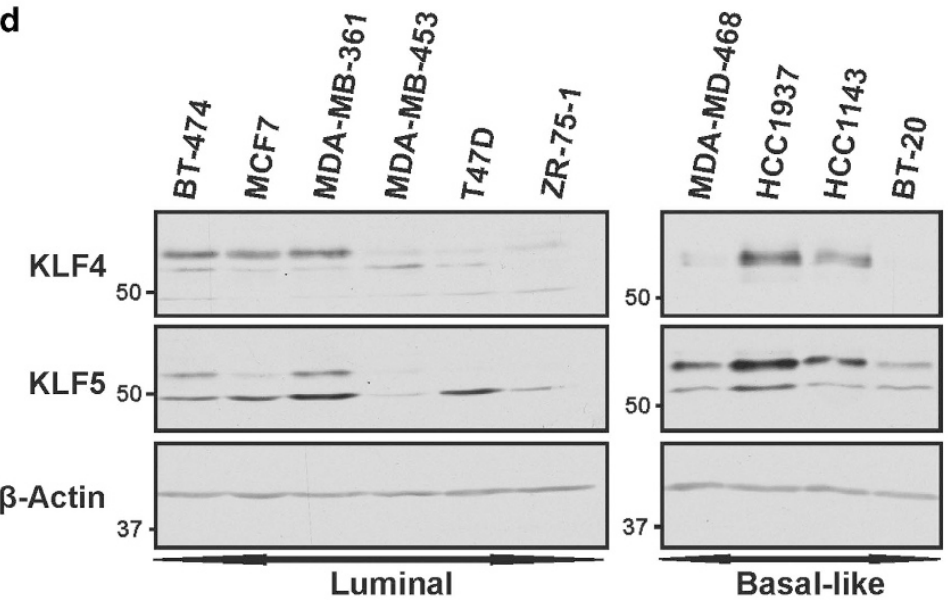

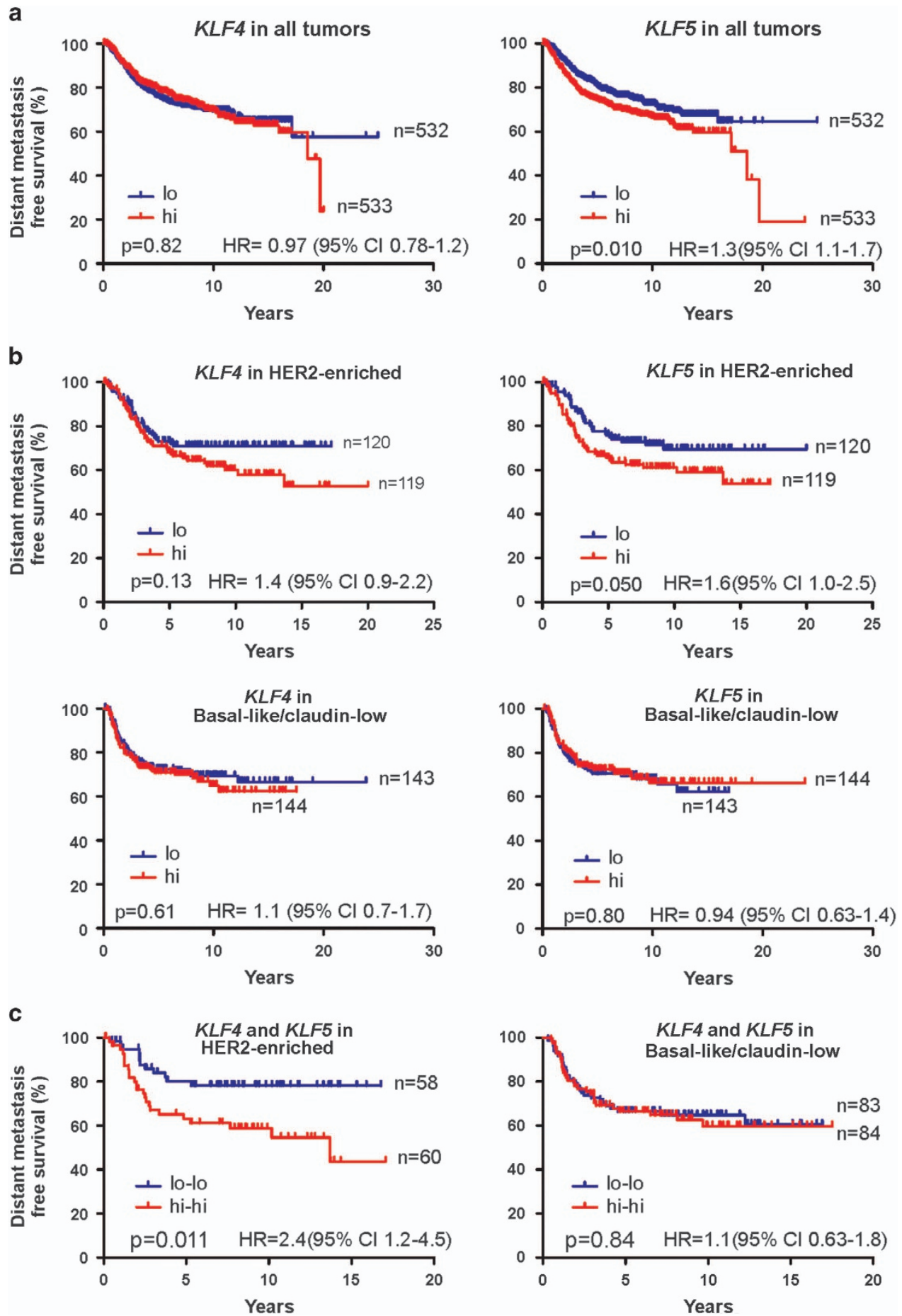

Figure 2 Prognostic significance of KLF4 and KLF5 in human breast cancer. Kaplan-Meier analysis utilized a previously described breast cancer microarray database. ${ }^{40}$ Red (hi) and blue (lo) groups were defined using the median gene expression level within the tumors of breast cancer patients. A total of 364 luminal A, 175 luminal B, $239 \mathrm{HER2-}$ enriched and 287 basal-like/claudin-low tumors were analyzed. (a) $K L F 4 / 5$ were analyzed as single variables for all tumors combined. (b) $K L F 4 / 5$ were analyzed as single variables within the basal-like/claudin-low and the HER2-enriched groups, as defined by PAM50 subtyping. (c) The outcome of patients harboring tumors with higher expression levels of both KLF4 and KLF5 (red, hi-hi) was compared with the outcome when tumors had lower expression levels of each factor (blue, lo-lo). For all curves, significance was determined using the log-rank (Mantel-Cox) test and $P<0.05$ was considered significant

elevated KLF5 was associated with shortened DMFS, consistent with prior observations (hazard ratio $(\mathrm{HR})$, 1.3; $95 \%$ confidence interval $(\mathrm{Cl}), 1.1-1.7 ; \quad P=0.01$; Figure 2a). ${ }^{11}$
Interestingly, analysis of DMFS in each intrinsic subtype revealed a trend for increased KLF5 expression and poor outcome in the HER2-enriched tumors (HR, 1.6; Cl, 1.0-2.5, nominal $P=0.05$; Figure $2 \mathrm{~b})$. Furthermore, $K L F 4$ expression 
showed a similar trend in this context $(\mathrm{HR}, 1.4 ; \mathrm{Cl}, 0.9-2.2$, $P=0.13)$. No such relationships were observed in a similarly high-risk group, basal-like/claudin-low (Figure 2b), nor in the luminal A or luminal B groups (Supplementary Figure 1). Furthermore, the expression of KLF4/5 together (i.e., $<$ median levels of each gene versus $\geq$ median levels of each gene) considerably stratified DMFS in the HER2enriched subtype (HR, 2.4; $\mathrm{Cl}, 1.2-4.5, P=0.011$; Figure 2c). HER2-enriched tumors with elevated KLF4/5 levels had DMFS similar to $43 \%$ at 15 years post-diagnosis. This effect was unique to the HER2-enriched subtype, as no other group showed any trend (Figure $2 \mathrm{c}$ and Supplementary Figure 1). To assess survival in patients with elevated expression of only one of the two KLFs, we analyzed the four survival curves defined by $2 \times 2$ contingency using the median scores for KLF4/5 (Supplementary Figure 1). The log-rank test for trend identified a significant trend between KLF4/5 expression and median DMFS $(P=0.016)$.

\section{Endogenous KLF4/5 are induced by lapatinib in breast} cancer. We next examined the transcript abundance of $K L F 4 / 5$ as determined by RNAseq analysis of patient breast tumors via The Cancer Genome Atlas (TCGA) Research Network. Among the breast cancer intrinsic subtypes, we observed the expression of the two factors to be most highly correlated in HER2-enriched tumors (Figure $3 a$ and Supplementary Figure 2). Given that KLF4/5 appeared to represent positively correlated prognostic factors in the HER2-enriched breast cancer subtype, we subsequently investigated the interdependence of KLF4/5 expression with exposure to, or resistance to, HER2-targeted therapy.

Interestingly, lapatinib promoted the expression of both the KLF4 and KLF5 proteins (Figure 3b). Trastuzumab treatment yielded similar results (Figure 3c). In these experiments, phosphorylated AKT levels served as a positive control for HER2 inhibition (Figures $3 b$ and c). These effects appeared to be transcriptionally independent, as the respective mRNA levels were not significantly altered (Figure 3d). Nor did enhanced efficiency of protein translation appear to account for upregulation of KLF4. Rather, the translational efficiency of the full-length KLF4 transcript, as determined using a previously described translation reporter, pMIR-Report-LucKLF4-FL, was actually decreased by lapatinib treatment (Figure 3e, left panel). ${ }^{18}$ This decrease is expected when KLF4 transcriptional activity is elevated, attributed to a wellcharacterized negative feedback signal by which KLF4 induces miR-206 and suppresses its own translation. ${ }^{18}$ Indeed, in lapatinib-treated cells the elevated KLF4 was associated with increased levels of miR-206, which can then directly target the KLF4 3' UTR (Figure 3e, right panel). ${ }^{18,20}$

As neither KLF4 transcription nor its translational efficiency appear to be upregulated by lapatinib, the results are consistent with lapatinib-mediated stabilization of the KLF4 protein. Therefore, lapatinib may function similarly to serum starvation to mediate a prolonged KLF4 half-life. ${ }^{42}$ Several experiments to directly assess half-life were unsuccessful because of the combined toxicity when cells were exposed to both lapatinib and the protein synthesis inhibitor cycloheximide. Nevertheless, the results indicate that lapatinib treatment of HER2-positive breast cancer cells can enhance KLF4 protein expression and its transcriptional activity as indicated by miR-206 levels.

Endogenous KLF4/5 mediate lapatinib resistance in breast cancer. Based on these results, we hypothesized that $\mathrm{KLF} 4 / 5$ are functionally important in the response to lapatinib. We therefore depleted KLF4/5 in HER2-amplified human BT474 and mouse M6 breast cancer cells, using distinct shRNA hairpins for each of the human and mouse genes (Figure 3f, left panels). M6 cells are a HER2overexpressing mammary cancer cell line derived from a basal-like GEMM that is enriched for KIf4/5, the C3(1) TAg model. ${ }^{43}$ Unlike many basal-like models, M6 cells overexpress both Egfr and Erbb2, the two RTKs targeted by lapatinib. Compared with the nontargeting control, single knockdown of KLF4 or KLF5 in the BT474 and M6 models significantly sensitized the cells to lapatinib treatment (Figure 3f, right panels). Moreover, coreduction of both KLF4/5 further sensitized the cells to lapatinib, indicating cooperativity. In these experiments, suppression of KLF5 led to a subtle reduction of KLF4, suggesting the possibility of crosstalk between the two factors (Figure 3f, left panels). In agreement with the knockdown studies, ectopic expression of $\mathrm{KLF} 4 / 5$ in M6 enhanced resistance to lapatinib treatment (Figure 3g).

To further characterize their role in drug resistance, we assessed mitochondrial membrane integrity (MMI) in these cells following lapatinib exposure (Figure $3 \mathrm{~h}$ ). Disruption of $\mathrm{MMI}$ is a key step of the intrinsic pathway of apoptosis. Following $24 \mathrm{~h}$ of lapatinib treatment, the single knockdown cell lines had reduced MMI compared with the controls and suppression of both KLF4/5 produced an additive effect. Supporting an impact of KLF4/5 on the intrinsic pathway of apoptosis, reduction of KLF4/5 enhanced cleaved caspase-9 following exposure to lapatinib, with additive effects when both KLFs were depleted (Figure 3i).

KLF4/5 cooperate to promote malignant properties. We next determined whether KLF4/5 contributed to malignant properties independently of lapatinib exposure. Relative to the control, depletion of either KLF4 or KLF5 in M6 cells significantly impacted anchorage-independent growth, as indicated by reduced colony-forming ability (Figure 4a). Furthermore, there was an additive reduction of colony number following codepletion. We similarly observed cooperativity in a gain-of-function context, as ectopic expression of KLF4/5 enhanced colony-forming ability in immortalized human breast epithelial cells (HMLE, Figure 4b).

Expanding on this observation, we evaluated the ability of these factors to impact tumor formation in athymic mice. Individual reduction of each KLF significantly reduced xenograft growth, with additive effects in the double knockdown cells (Figure 4c, left panel). Comparable results on tumor formation were obtained using an independent shRNA to target each factor (Figure 4c, right panel).

To determine whether these results reflect deficiencies in prosurvival signaling, we examined whether KLF4/5 could cooperatively influence cell death following matrix deprivation (anoikis). Single knockdown of KLF4 or KLF5 sensitized cells to anoikis as determined by Trypan blue exclusion, with 

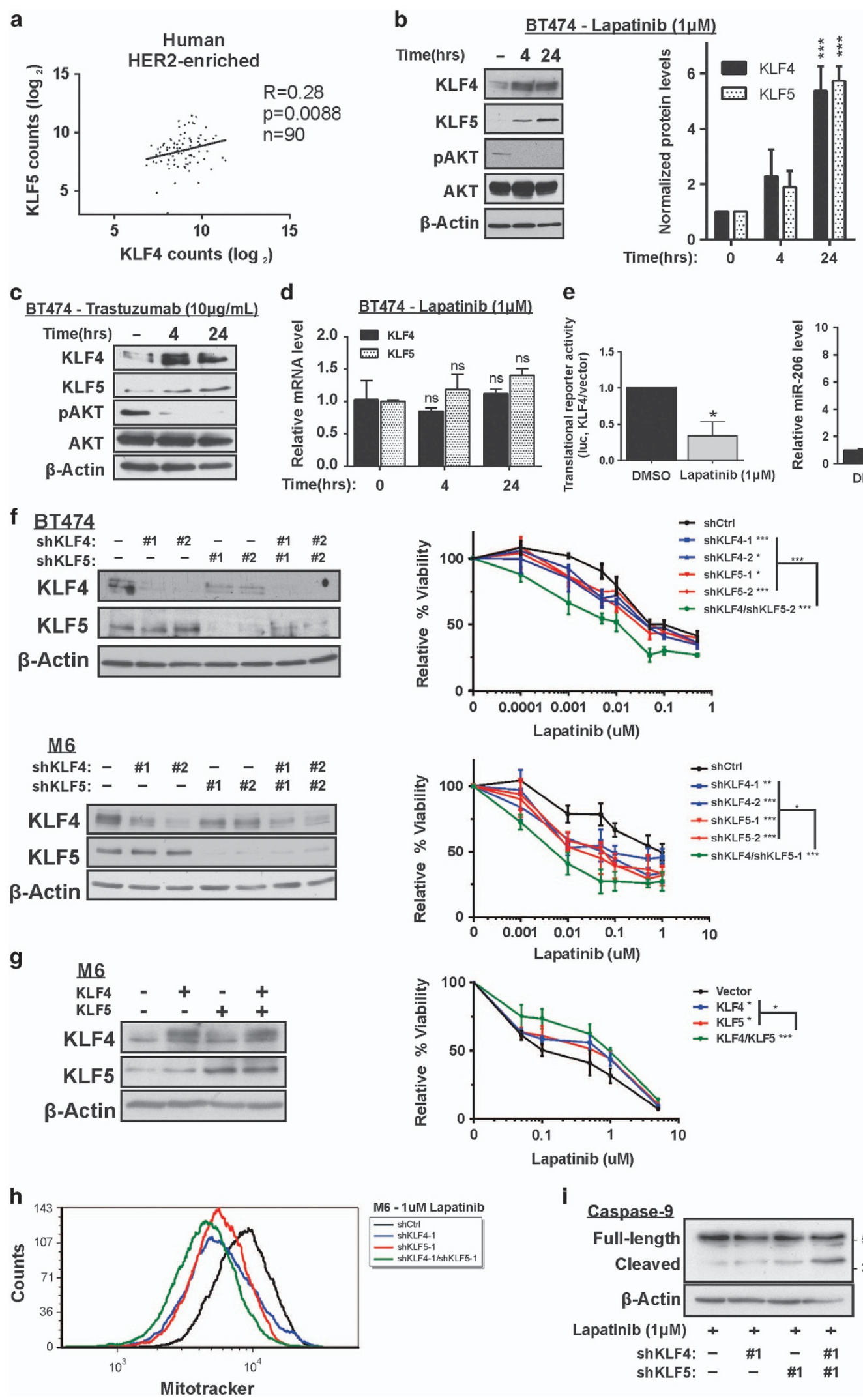

cooperative effects following codepletion (Figure 4d, left panel). Conversely, overexpression of these factors in HMLE enhanced anoikis resistance (Figure 4d, right panel). Determination of cell death by an independent method yielded similar results (Figure 4e).

KLF4/5 depletion is associated with reduced expression of anti-apoptotic B-cell lymphoma 2 (BCL2) family members. As KLF4/5-depleted cells consistently exhibited defects in cell survival, we analyzed molecular effectors of this phenotype. The intrinsic pathway of apoptosis is critical in both lapatinib resistance and anoikis. ${ }^{44} \mathrm{We}$ therefore examined the association of KLFs with factors known to participate in apoptotic signaling.

In response to lapatinib or trastuzumab treatment, we observed induction of not only KLF4/5 (Figures $3 b$ and d), but also the anti-apoptotic BCL2 members BCL2, BCL-XL (BCL2L1) and MCL1 (Figure 5a). Although BCL2 was increased in response to lapatinib, BCL2 levels were decreased upon trastuzumab exposure, consistent with previous studies. ${ }^{45}$ Despite the well-documented oncogenic role for BCL2 in hematological malignancies, its expression is correlates with a favorable patient outcome in breast cancer. ${ }^{46}$

Single knockdown of either KLF4 or KLF5 greatly reduced BCL-XL levels in untreated M6 and BT474 cells (Figures 5b and $\mathrm{c}$, left panel). Interestingly, human KPL4 cells required depletion of both KLFs to impact BCL-XL abundance, possibly attributed to the activating phosphatidylinositide 3-kinase (PI3K) mutation present in this HER2-amplified, inflammatory breast cancer cell line (Figure $5 b) .{ }^{47}$

In both BT474 and KPL4 cells, a reduction of the MCL1 protein level was evident when KLF4/5 were cosuppressed (Figure 5b). Owing to lack of a suitable antibody, we could not reliably detect murine MCL1 (Figure 5c, left panel). Regardless, in these cells the KLFs cooperated to maintain Mcl1 and $\mathrm{Bcl}-\mathrm{x} /$ transcript levels, as shown by qRT-PCR (Figure $5 \mathrm{c}$, right panel). Ectopic expression of KLF4/KLF5 in HMLE cells cooperated to increase MCL1 expression, however, BCL-XL levels responded primarily to KLF4 (Figure $5 d$ ).

Although the KLFs impacted BCL2 levels in M6 cells, this regulation was not apparent in BT474 cells (Figures 5b and c). qRT-PCR transcript analysis of other BCL2 family members including Bad, Bax and Bid revealed no significant effects by modulation of the two KLFs (data not shown).

To extend these in vitro studies, we assessed the copresence of $K L F 4 / 5$ expression with MCL1, BCL-XL and/or
$B C L 2$ in human tumors (Table 1). ${ }^{48,49}$ Using a $\pm 1.5 z$-score range to define high and low expression groups, we evaluated the mutual exclusivity/inclusivity in 958 human breast tumors that were analyzed by microarray. Both $K L F 4 / 5$ cooccurred with MCL1. In addition, KLF4 and BCL-XL expression levels were mutually inclusive, as were $K L F 5$ and $B C L 2$. In agreement with our previous observations (Figure $3 a$ ), $K L F 4 / 5$ expression cooccurred in these tumors.

To more directly test for a correlation in patient samples, we utilized the RNAseq database generated by TCGA. Across 890 breast tumors, the transcript abundance for KLF4, KLF5 and MCL1 was positively correlated (Figure $5 e$ ). Using this data set, we observed no significant positive correlations between KLFs and the other anti-apoptotic genes, BCL-XL and BCL2 (data not shown). Despite these results, extensive ChIP studies in BT474 cells that analyzed 5-kbp upstream of the transcriptional start site, the body of the gene and 3-kbp downstream, failed to identify any KLF4/5 association with the mouse or human MCL1 loci (see Discussion section).

We next examined whether KLF4/5 expression was required for the induction of anti-apoptotic molecules by lapatinib. We focused on MCL1, as this molecule displayed a robust induction following HER2 inhibition and exhibited consistent relationships with the KLFs in human tumors (Table 1,Figures $5 a$ and e). To ensure a suitable number of viable, lapatinib-sensitive KLF-depleted cells for analysis we used a reduced lapatinib concentration of $250 \mathrm{nM}$. Although individual reduction of KLF4 or KLF5 did not substantially impact the lapatinib-mediated induction of MCL1 (data not shown), cosuppression of both KLFs blunted this response (Figure 5f).

To validate the importance of MCL1 in lapatinib resistance, we reduced MCL1 levels in BT474 cells using siRNA smart pool (Figure 5g). Compared with the nontargeting control, siMCL1 cells demonstrated increased sensitivity to lapatinib treatment. Similarly, a small molecule MCL1 inhibitor, UMI-77, yielded comparable results to the siRNA studies (data not shown). Conversely, MCL1 overexpression in KLF4/5 knockdown BT474 cells was sufficient to restore lapatinib resistance (Figure 5h).

\section{Discussion}

Targeted therapies have significantly improved the DFS of breast cancer patients, including patients with ER+ or HER2+ breast cancers, and these therapies hold promise for triple-

Figure 3 Endogenous KLF4/5 mediate lapatinib resistance in breast cancer models. (a) Levels of KLF4/5 in primary human breast tumors were determined by RNAseq (Illumina HiSeq RNAseqV2). Upper quartile normalized data were downloaded from TCGA and assigned a PAM50 subtype. Spearman's correlation was performed on the log 2 transformed data. (b) BT474 cells were treated with DMSO or lapatinib for the indicated interval. Whole-cell lysate was analyzed by western blot. Expression levels from three independent experiments were determined using ImageJ for quantitation, with normalization to $\beta$-actin (bars, S.D.). (c) BT474 cells were treated with trastuzumab or sterile water for the indicated interval and whole-cell lysate was analyzed by western blot. (d) KLF4/5 transcript levels were determined by qRT-PCR following lapatinib exposure. Expression data were normalized using the housekeeping gene B2M. (e) The pMIR-Report-Luc-KLF4-FL translation reporter contains as an insert within the FLuc 3' UTR the full-length KLF4 transcript, including the KLF4 protein coding region and the flanking UTRs, as previously described. ${ }^{18}$ Translation efficiency was measured by determining normalized Fluc activity in BT474 cells treated for $24 \mathrm{~h}$ with lapatinib or DMSO (left panel). miR-206 levels were determined by qRT-PCR following 24-h lapatinib exposure. Expression data were normalized using U6 snRNA (right panel). (f) Cells were treated with the indicated shRNA construct, and the resulting cell populations were treated with lapatinib for $96 \mathrm{~h}$. For each cell population, cell viability relative to the DMSO control was obtained via ATP-based luminescence assay (bars, S.D.). (g) Similarly, the lapatinib effect on the relative cell viability of M6 cells expressing ectopic KLF4 and/or KLF5 was determined. Empty vector served as a control. (h) To assess MMl, M6 cells were treated with lapatinib for $24 \mathrm{~h}$, stained with $250 \mathrm{nM}$ of Mitotracker dye and analyzed by flow cytometry. (i) To assess activity of the intrinsic apoptotic pathway, caspase-9 levels were determined in M6 cells expressing shCtl, shKLF4, shKLF5 or shKLF4/5. Cells were treated with lapatinib for $24 \mathrm{~h}$ before preparation of cell extracts. ${ }^{*} P<0.05 ;{ }^{* \star} P<0.01 ;{ }^{* \star *} P<0.001$ 
a
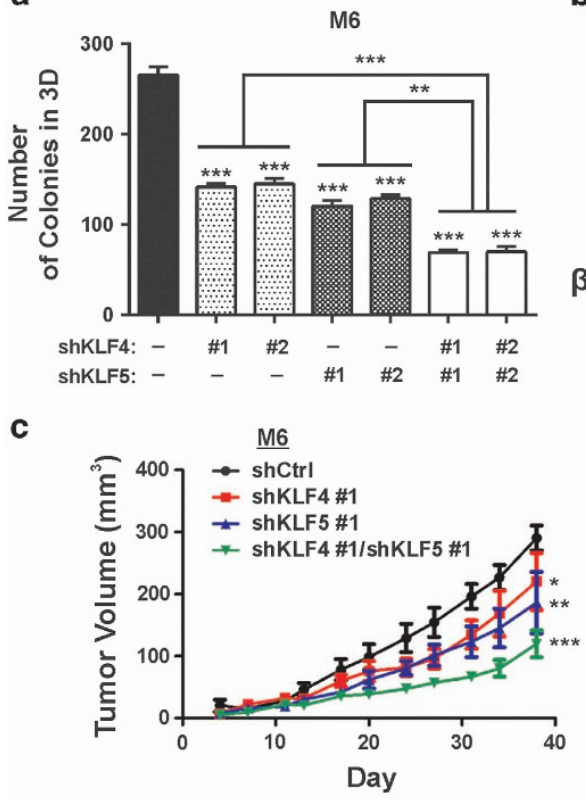

d

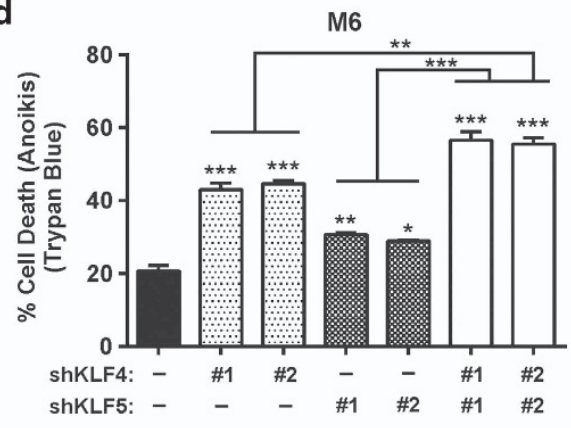

b

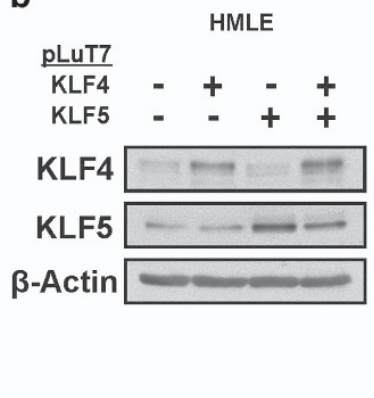

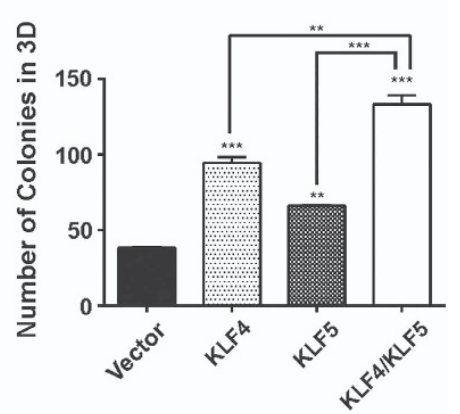

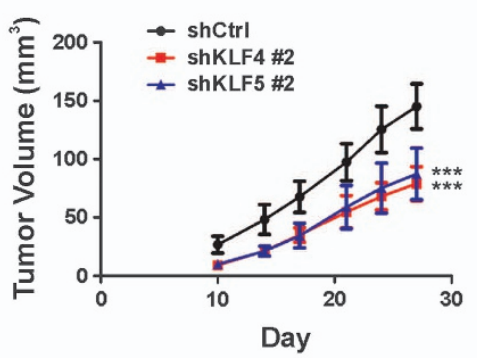

HMLE

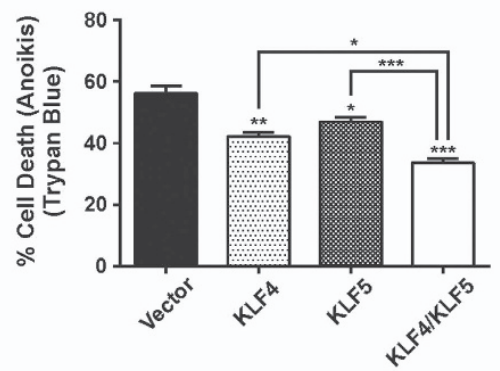

e

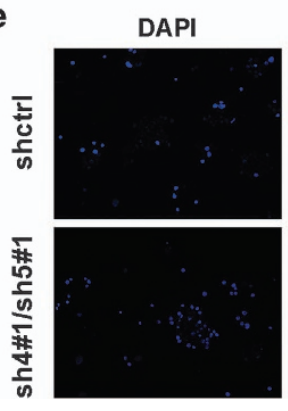

PI

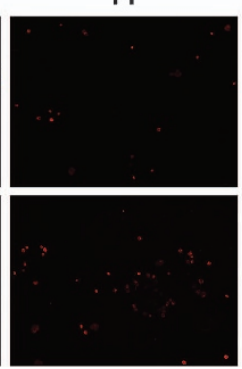

Merge
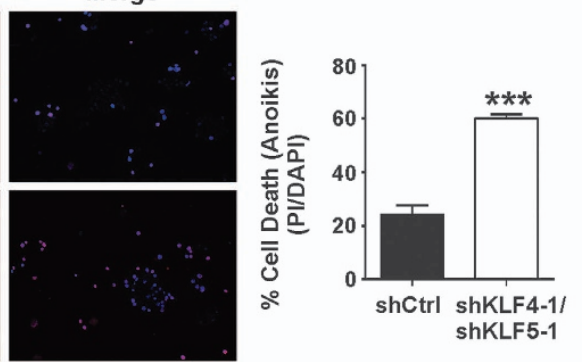

Figure 4 KLF4/5 cooperate to promote malignant properties in M6 cells, a HER-2-overexpressing mammary cancer model. (a) Anchorage independence was assessed by incubation of the indicated cell populations in soft agar for 14 days ( $N=3$, bars, S.E.). (b) Anchorage independence of HMLE cells expressing ectopic KLF4/5 was determined as previously described. Empty vector (-) served as a control so that all cell populations were treated with equal volumes of lentiviral supernatant. (c) Cells were injected into the mammary gland of female athymic mice and tumor xenograft volume was monitored over a period of several weeks (left panel, $N=5$; bars, S.E.). Similar effects on tumor burden were obtained using distinct shRNAs for the suppression of each KLF (right panel, $N=5$; bars, S.E.). (d) Cell death was determined by Trypan blue exclusion following $24 \mathrm{~h}$ of matrix deprivation for the indicated cell populations ( $N=3$; bars, S.E.). (e) As an independent method, cell death because of matrix deprivation in M6 cells was determined by fluorescence microscopic imaging of DAPI/PI-stained cells. Results were quantitated using ImageJ (two-tailed $t$-test; $N=3$; bars, S.E.). ${ }^{\star} P<0.05 ;{ }^{* \star} P<0.01 ;{ }^{* \star \star} P<0.001$

negative breast cancer (TNBC), particularly when used in combination. $^{36,37}$ For HER2+ breast cancer, clinically approved therapies include the monoclonal antibodies trastuzumab and pertuzumab and, for third- or fourth-line therapy of metastatic disease, the small molecule lapatinib.

For intrinsically aggressive breast cancers such as HER2enriched tumors, therapeutic resistance is common, as evidenced by the progression of unresponsive tumors. ${ }^{23-26}$ Similar to lapatinib and trastuzumab, it is likely that resistance mechanisms will impact the newer classes of HER2/EGFR inhibitors, such as neratinib. ${ }^{50}$ Therefore, a better understanding of the molecular drivers of resistance could enable the identification of effective drug combinations to improve clinical efficacy. 
a

BT474

Lapatinib $(1 \mu \mathrm{M})$ Trastuzumab $(10 \mu \mathrm{g} / \mathrm{mL})$

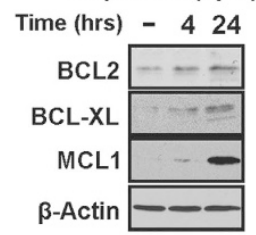

b

BT474

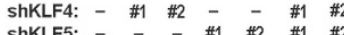

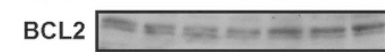

BCL-XL

MCL1 $\ldots \ldots$

$\beta$-Actin $-\infty$

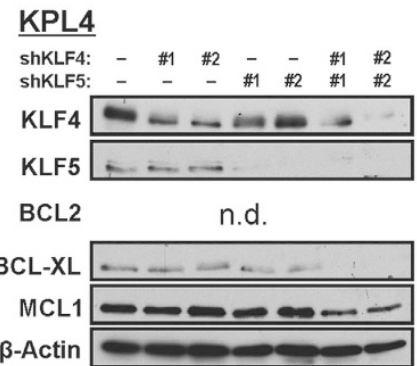

d

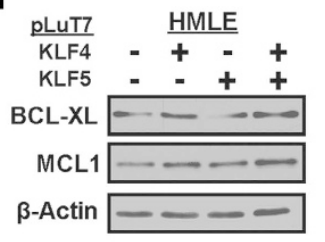

C

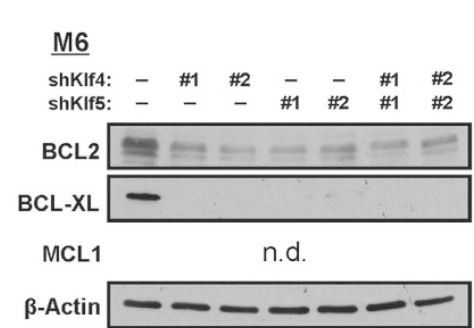

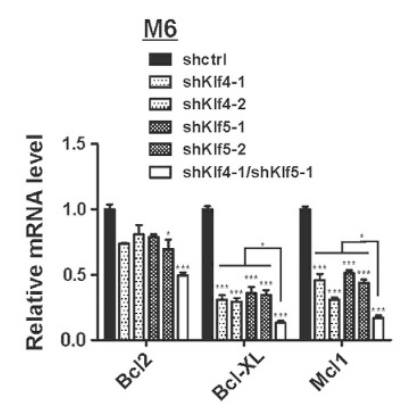

f e

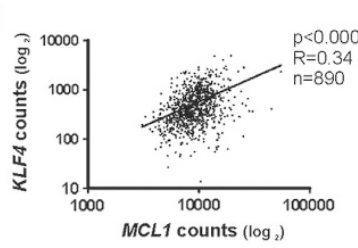

g

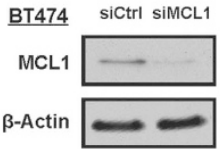

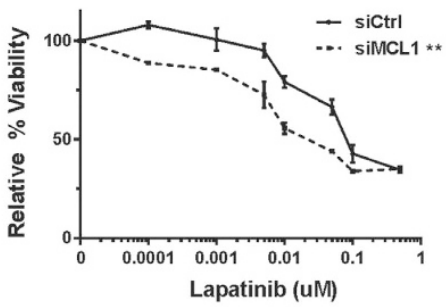

h

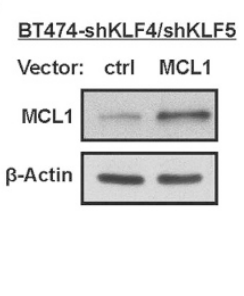

BT474 shCtrl shKLF4/shKLF5

Lapatinib(250nM): - +

MCL1

$\beta$-Actin
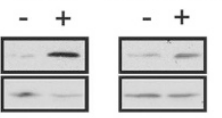

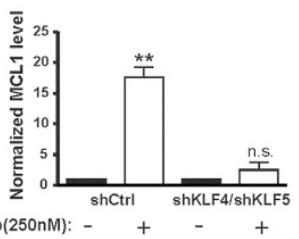

Lapatinib(250nM): - + - 
Table 1 The expression levels of KLF4/5 in breast cancer are mutually inclusive with the anti-apoptotic BCL2 family members

\begin{tabular}{lccccc}
\hline Gene & \multirow{2}{*}{ BCL-XL } & BCL2 & MCL1 & KLF5 & KLF4 \\
\hline BCL-XL & - & $1.22 \mathrm{E}-1$ & $1.59 \mathrm{E}-1$ & $1.78 \mathrm{E}-1$ & $\mathbf{1 . 0 0 E - 2}^{\mathrm{a}}$ \\
BCL2 & & - & $\mathbf{6 . 9 8 \mathrm { E } - 4 ^ { \mathrm { a } }}$ & $\mathbf{2 . 3 0 \mathrm { E } - 5 ^ { \mathrm { a } }}$ & $2.52 \mathrm{E}-1$ \\
MCL1 & & & - & $\mathbf{1 . 2 8 E - 2}^{\mathrm{a}}$ & $\mathbf{9 . 0 0 \mathrm { E } - 6 ^ { \mathrm { a } }}$ \\
KLF5 & & & & - & $<\mathbf{1 . 0 0 E - 6}^{\mathrm{a}}$ \\
KLF4 & & & & & -
\end{tabular}

Using cBioPortal, the mutual inclusivity/exclusivity of KLF4/5 and anti-apoptotic BCL2 family member expression was assessed in 958 human breast tumors using $a \pm 1.5 z$-score range. Transcript abundance was determined by microarray. $P$-values were obtained by Fisher's exact $T$-test (bold indicates significance)

${ }^{a}$ Denotes an odds ratio (OR) range of $2-10$. For this analysis, OR $>2.0$ signifies cooccurrence of expression within the tumor subsets as defined by the $z$-score

by analysis of the KLF4/5-deficient cells. We are currently assessing other tumor models for KLF4/5-dependent upregulation of anti-apoptotic factors in response to small molecule inhibitors.

There are only a few established links between the KLFs, anti-apoptotic BCL2 family proteins and HER2. ${ }^{52-54}$ In this study, we observed coexpression of KLF4/5 and MCL1 in human breast tumors and breast cancer models. Also, in mouse ES cells the Mcl1 locus was significantly enriched via ChIP-seq using antibodies to either KLF4 or KLF5. ${ }^{2,55}$ Despite these results, and the clear dependence of MCL1 on KLF4/5 expression (Figures $5 \mathrm{~b}$ and $\mathrm{c}$ ), the MCL1 locus was not enriched in KLF4/5 ChIP assays, in which MIR206 served as a positive control (data not shown). ${ }^{20}$ These results suggest an indirect relationship, although the possibility of direct regulation through a distal binding site cannot be excluded.

We found that $K L F 4 / 5$ mRNA levels were correlated most strongly in the HER2-enriched tumors, and these factors were selectively prognostic within this subtype. Previous studies have linked adverse clinical outcome to increased nuclear localization of KLF4, to elevated KLF5 mRNA and to promoter demethylation of KLF4 or KLF5. ${ }^{10-14}$ In our study, we observed shortened DMFS for patients with HER2-enriched tumors containing elevated levels of both KLF4 and KLF5, implicating these two KLFs as novel prognostic factors (Figure 2d).

In any single breast tumor subtype or in all tumors combined, KLF4 on its own had little effect (Figure 2b). In contrast to these results, a previous study associated elevated KLF4 transcript levels with prolonged DFS. ${ }^{56}$ As overall survival, DFS and DMFS correlate strongly in breast cancer, the utilization of these different endpoints seems unlikely to account for the distinct results. ${ }^{57-59}$ Instead, the discrepancy may be attributed to the analysis of different patient populations, to differences in sample size or to methodological differences in sample processing.

This study identifies a novel drug resistance program composed of KLF4/5, with likely origins in the stress response signaling of KLFs in normal cells. In response to deficient RTK signaling, KLF4/5 can coordinate a prosurvival response that includes BCL2 family proteins, miR-206 and likely other factors. Future studies will examine the predictive utility of KLF4/5 for guiding patient therapy, for example, in patients with HER2+ tumors. Taken together, the identification of KLF4/5 as intermediaries between HER2 and the BCL2 family members significantly strengthens the rationale for combined therapeutic inhibition of HER2 and BCL-XL/MCL1 to combat drug resistance.

\section{Materials and Methods}

Cell lines and tissue culture. M6 cells were obtained from Jeffrey $E$ Green (National Cancer Institute, Bethesda, MD, USA), KPL4 cells were from Afsaneh Keyhani (MD Anderson, Houston, TX, USA) and HMLE cells were from Robert A Weinberg (Whitehead Institute, Cambridge, MA, USA). Cells were cultured as previously described. ${ }^{51,60,61}$ T47D, BT-20, ZR-75-1, MCF7, HCC1937, BT474 and HCC1143 cell lines were purchased from ATCC (Manassas, VA, USA) and cultured in RPMI 1640. MDA-MB-453 cells were cultured in DMEM, whereas MDA-MB-361 and MDA-MB-468 were cultured in DMEM/Ham's F12 50:50. All were supplemented with $10 \%$ (v/v) FBS (Hyclone, GE Healthcare Life Sciences, Logan, UT, USA), penicillin and streptomycin. Lapatinib (Selleck, Boston, MA, USA) was dissolved in DMSO and used at the indicated concentrations. Trastuzumab (Herceptin) was obtained from the Mary Babb Randolph Cancer Center (Morgantown, WV, USA).

Transfections and retroviral transduction. The control shRNA vector (nonsilencing-GIPZ lentiviral shRNA control (shCtr); RHS4346) and the shRNA vectors for murine Klf4 (V3LMM_459916, V3LMM_524009), murine Klf5 (V3LMM_489119, V2LMM_73715) and human KLF5 (V2LHS_150118 and V2LHS_150120) were purchased from Open Biosystems (Pittsburgh, PA, USA). shRNAs targeting human KLF4 have been previously described. ${ }^{20}$

siMCL1 ON-TARGETplus smart pool was purchased from Dharmacon (Lafayette, CO, USA) and transfected using Lipofectamine RNAiMAX Reagent, Life Technologies (Grand Island, NY, USA), as per the manufacturer's recommendations.

Luciferase-based reporter assay of translational efficiency was performed as previously reported, using pMIR-Report-Luc-KLF4-FL and with normalization to pRL-TK. ${ }^{18}$

$\mathrm{KLF} / 5$ were expressed in human cells using the lentiviral vector, pLuT7. KLF4 was ectopically expressed in M6 cells using pBabe-puro-KLF4. ${ }^{18}$ pBabe-puro MCL1 was a gift from Roger Davis (Addgene, Cambridge, MA, USA; plasmid \# 25371). ${ }^{62}$ Vectors were packaged into viral particles as previously described. ${ }^{18}$ Cells were infected with viral supernatant supplemented with $10 \mu \mathrm{g} / \mathrm{ml}$ polybrene, centrifuged at 2500 r.p.m. for $1.5 \mathrm{~h}$ at $30^{\circ} \mathrm{C}$ and selected in puromycin $(1.0 \mu \mathrm{g} / \mathrm{ml})$.

Immunoblot analysis. Cell lysis, gel electrophoresis, transfer and immunoblot analysis was performed as described. ${ }^{18}$ Primary antibodies were KLF4 ( $\mathrm{H} 180$, Santa Cruz, Dallas, TX, USA), KLF5 (Millipore, Billerica, MA, USA), MCL1 (S19, Santa Cruz), BCL-XL (L19, Santa Cruz), BCL2 (clone 7/Bcl-2, BD Biosciences, San Jose, CA, USA), phospho-AKT(Ser473, Cell Signaling, Danvers, MA, USA), AKT (Cell Signaling), Caspase-9 (Cell Signaling, 9502) and $\beta$-actin (C-4, Sigma, St. Louis, MO, USA).

Animal studies. C3(1) TAg mice and MMTV-Neu mice (202Mul) were obtained from Jax Labs (Bar Harbor, ME, USA). Female athymic nude mice (Charles River, Frederick, MD, USA) were obtained at 6-8 weeks of age. In all, $2.0 \times 10^{6}$ cells were injected into the fourth mammary fat pad in $100 \mu \mathrm{l}$ of DMEM. Caliper measurements were performed twice per week to measure tumor volume. Tumor volume was calculated according to $\pi\left(\mathrm{L} 1 \times \mathrm{L} 2^{2}\right) / 6$ (L1, long axis; L2, short axis). All animal procedures were performed under an approved ACUC protocol.

Quantitative, real-time, reverse transcription and PCR analysis of mRNA. Mouse breast tumors or normal mammary glands were harvested from killed mice and snap frozen. Tissue was mechanically dissociated using glass beads and total RNA was isolated as previously described. ${ }^{63}$ For cell lines, total RNA was extracted using the RNeasy minikit (Qiagen, Valencia, CA). gRT-PCR was performed as previously described. ${ }^{18}$ Primers used for qRT-PCR can be found in Supplementary Table 1 . Of the housekeeping genes analyzed using RNA from normal mouse mammary gland and tumors, including $\mathrm{Rp} / \mathrm{pO}$, Gapdh and $\mathrm{B} 2 \mathrm{~m}$, the Rplpo levels showed the best correlation with total RNA quantity. Gene expression assays were therefore normalized using this transcript. ${ }^{64}$

Gene expression analysis of human breast tumors. Data generated using the UNC Illumina HiSeq RNAseqV2 plattorm were downloaded from TCGA (http://apps.nhlbi.nih.gov/grasp/, 11 March 2013). Statistical programming software $\mathrm{R}$ (version 3.0.1) was used to assemble and process the data. Molecular subtyping 
was accomplished using the Bioconductor 2.12 genefu R package. ${ }^{65}$ At the time of this study, patient follow-up data for TCGA samples were not sufficiently mature for survival analysis. For survival analyses, the compendium of gene expression array data sets of breast cancer was previously compiled, with subtypes assigned as described elsewhere.40,66 Probes used for KLF4/5 were 221841_s_at and 209211_at, respectively.

Luminescence based cell viability assay. In all, $2 \times 10^{3}$ cells per well (BT474) or $5 \times 10^{2}$ cells per well (M6) were transferred to 96 -well plates and cultured for $96 \mathrm{~h}$ in the indicated concentrations of lapatinib. Five replicates were used for each concentration of drug. Fresh media and lapatinib was added to the cells after $48 \mathrm{~h}$. Viable cell number was determined via the ATPlite Luminescence ATP Detection Assay System (PerkinElmer, Waltham, MA, USA) Relative percent viability was determined by normalizing each condition to DMSO treatment only.

Anoikis sensitivity assays. The anoikis procedure and quantitation of cell death by Trypan blue exclusion was previously described..$^{20}$ Alternatively, cell death was determined using fluorescent microscopic analysis (Zeiss Axio Imager Z2, Oberkochen, Germany) of cells stained with propidium iodide (PI) and 4',6diamidino-2-phenylindole (DAPI) to identify dead cells and total cell number, respectively. ${ }^{67}$ Quantitation of PI/DAPI-stained cells was performed using Image $J$ (National Institutes of Health, Bethesda, MD, USA).

Soft agar colony formation. SeaPlaque agarose (Lonza, Anaheim, CA, USA) was dissolved in $1 \mathrm{X}$ PBS and autoclaved. The agar layers contained complete growth media and consisted of $1.0 \mathrm{ml} 0.5 \%$ (w/v) agar underlay, $2.0 \mathrm{ml}$ of $0.5 \%$ agar cell layer containing $1.5 \times 10^{3}$ cells $/ \mathrm{ml}$ and $1 \mathrm{ml}$ of $0.3 \%$ agar overlay per well of a six-well plate. In all, $250 \mu \mathrm{l}$ of growth media was added onto the top layer. The plates were wrapped in parafilm and incubated at $37^{\circ} \mathrm{C}$ for 14 days, with an additional $250 \mu$ l of complete growth media added after 7 days. Colonies were visualized with a Perfection vV700 Photo scanner (Epson, Long Beach, CA, USA) and colonies $>200 \mu \mathrm{m}$ were counted.

Flow cytometry. Following $24-\mathrm{h}$ treatment with $1 \mu \mathrm{M}$ lapatinib, $5.0 \times 10^{5} \mathrm{M} 6$ cells were washed twice with PBS, resuspended in $300 \mu$ l PBS containing $250 \mathrm{nM}$ Mitotracker Deep Red dye (Invitrogen/GE Healthcare, Logan, UT, USA), and incubated at room temperature for $30 \mathrm{~min}$. Stained cells were centrifuged at low speed and then resuspended in PBS and analyzed in a BD FACS Calibur flow cytometer (BD Biosciences) using BD CellQuest Pro software (BD Biosciences). Plots were generated using FCS Express 4 (De novo software, Glendale, CA, USA).

Statistical analysis. Statistical analyses were performed in GraphPad Prism 6 (GraphPad Software, San Diego, CA, USA). RNA samples were independently analyzed by qRT-PCR three times in duplicate manner (column, mean; bars, S.E.). Correlations were obtained using Spearman's correlation. Xenograft and drug sensitivity assays were analyzed by repeated measures one-way analysis of variance (ANOVA) followed by Tukey's multiple comparison post test. Other assays including soft agar growth and anoikis were assessed by one-way ANOVA followed by Tukey's post test. Differences were considered significant when two-sided analysis yielded $P<0.05$.

\section{Conflict of Interest}

The authors declare no conflict of interest.

Acknowledgements. This work was supported by grants NCI R01 CA127405 (to JMR), the Jo and Ben Statler Chair in Breast Cancer Research, and the Wilmer V and Helen B Morley Memorial Fund at the Mary Babb Randolph Cancer Center (MBRCC). Flow cytometry experiments were performed in the West Virginia University Flow Cytometry Core Facility, which is supported by NIH equipment grant RR020866 and the Institutional Development Award (IDeA) from the National Institute of General Medical Sciences under grants P30GM103488 (CoBRE) and P20GM103434 (INBRE). Animal work and imaging experiments were performed in the West Virginia University Microscope Imaging Facility and West Virginia University Animal Models and Imaging Facility, which was supported by the MBRCC and $\mathrm{NIH}$ grants P20 RR016440, P30 RR032138/GM103488, P20 RR016477 and S10 RR026378. Work performed at the Statistics and Bioinformatics Core Resources of the Dan L Duncan Cancer, Baylor College of Medicine, was supported by NCl grant P30 CA125123. We thank William Petros for the generous gift of trastuzumab (MBRCC) and Fengju Chen (Baylor College of Medicine) for assistance with gene expression analysis. In addition, we thank Jeffrey E Green for C3(1) TAg mice and M6 cells, Laura F. Gibson for sharing several antibodies, Afsaneh Keyhani for the KPL4 cell line and Robert A.Weinberg for donating HMLE cells.

1. Jiang J, Chan YS, Loh YH, Cai J, Tong GQ, Lim CA et al. A core Klf circuitry regulates selfrenewal of embryonic stem cells. Nat Cell Biol 2008; 10: 353-360.

2. Aksoy I, Giudice V, Delahaye E, Wianny F, Aubry M, Mure M et al. Klf4 and Klf5 differentially inhibit mesoderm and endoderm differentiation in embryonic stem cells. Nat Commun 2014; 5. 3719

3. McConnell BB, Ghaleb AM, Nandan MO, Yang VW. The diverse functions of Kruppel-like factors 4 and 5 in epithelial biology and pathobiology. Bioessays 2007; 29: 549-557.

4. Swamynathan SK, Katz JP, Kaestner KH, Ashery-Padan R, Crawford MA, Piatigorsky J. Conditional deletion of the mouse Klf4 gene results in corneal epithelial fragility, stromal edema, and loss of conjunctival goblet cells. Mol Cell Biol 2007; 27: 182-194.

5. Kenchegowda D, Swamynathan S, Gupta D, Wan H, Whitsett J, Swamynathan SK. Conditional disruption of mouse Klf5 results in defective eyelids with malformed meibomian glands, abnormal cornea and loss of conjunctival goblet cells. Dev Biol 2011; 356: 5-18.

6. Pedersen TX, Leethanakul C, Patel V, Mitola D, Lund LR, Dano K et al. Laser capture microdissection-based in vivo genomic profiling of wound keratinocytes identifies similarities and differences to squamous cell carcinoma. Oncogene 2003; 22: 3964-3976.

7. Zhao Y, Hamza MS, Leong HS, Lim CB, Pan YF, Cheung E et al. Kruppel-like factor 5 modulates p53-independent apoptosis through Pim1 survival kinase in cancer cells. Oncogene 2008; 27: 1-8

8. Li X, Liu X, Xu Y, Liu J, Xie M, Ni W et al. KLF5 promotes hypoxia-induced survival and inhibits apoptosis in non-small cell lung cancer cells via HIF-1alpha. Int J Oncol 2014; 45: 1507-1514.

9. Talmasov D, Xinjun Z, Yu B, Nandan MO, Bialkowska AB, Elkarim E et al. Kruppel-like factor 4 is a radioprotective factor for the intestine following gamma-radiation-induced gut injury in mice. Am J Physiol Gastrointest Liver Physiol 2015; 308: G121-G138.

10. Pandya AY, Talley LI, Frost AR, Fitzgerald TJ, Trivedi V, Chakravarthy $M$ et al. Nuclear localization of KLF4 is associated with an aggressive phenotype in early-stage breast cancer. Clin Cancer Res 2004; 10: 2709-2719.

11. Tong D, Czerwenka K, Heinze G, Ryffel M, Schuster E, Witt A et al. Expression of KLF5 is a prognostic factor for disease-free survival and overall survival in patients with breast cancer. Clin Cancer Res 2006; 12: 2442-2448.

12. Ben-Porath I, Thomson MW, Carey VJ, Ge R, Bell GW, Regev A et al. An embryonic stem cell-like gene expression signature in poorly differentiated aggressive human tumors. Nat Genet 2008; 40: 499-507.

13. Chen CJ, Lin SE, Lin YM, Lin SH, Chen DR, Chen CL. Association of expression of Kruppellike Factor 4 and Kruppel-like Factor 5 with the clinical manifestations of breast cancer. Pathol Oncol Res 2012; 18: 161-168.

14. Kamalakaran S, Varadan V, Giercksky Russnes HE, Levy D, Kendall J, Janevski A et al. DNA methylation patterns in luminal breast cancers differ from non-luminal subtypes and can identify relapse risk independent of other clinical variables. Mol Oncol 2011; 5: 77-92.

15. Rowland BD, Bernards R, Peeper DS. The KLF4 tumour suppressor is a transcriptional repressor of p53 that acts as a context-dependent oncogene. Nat Cell Biol 2005; 7: 1074-1082.

16. Zheng HQ, Zhou Z, Huang J, Chaudhury L, Dong JT, Chen C. Kruppel-like factor 5 promotes breast cell proliferation partially through upregulating the transcription of fibroblast growth factor binding protein 1. Oncogene 2009; 28: 3702-3713.

17. Yu F, Li J, Chen H, Fu J, Ray S, Huang S et al. Kruppel-like factor 4 (KLF4) is required for maintenance of breast cancer stem cells and for cell migration and invasion. Oncogene 2011; 30: 2161-2172

18. Lin CC, Liu LZ, Addison JB, Ivanov AV, Ruppert JM. A KLF4-miRNA-206 autoregulatory feedback loop can promote or inhibit protein translation depending upon cell context. Mol Cell Biol 2011; 31: 2513-2527.

19. Zhao D, Zhi X, Zhou Z, Chen C. TAZ antagonizes the WWP1-mediated KLF5 degradation and promotes breast cell proliferation and tumorigenesis. Carcinogenesis 2012; 33: 59-67.

20. Sharma SB, Lin CC, Farrugia MK, McLaughlin SL, Ellis EJ, Brundage KM et al. microRNAs206 and -21 cooperate to promote RAS-ERK signaling by suppressing the translation of RASA1 and SPRED1. Mol Cell Biol 2014; 34: 4143-4164.

21. Cobleigh MA, Vogel CL, Tripathy D, Robert NJ, Scholl S, Fehrenbacher L et al. Multinational study of the efficacy and safety of humanized anti-HER2 monoclonal antibody in women who have HER2-overexpressing metastatic breast cancer that has progressed after chemotherapy for metastatic disease. J Clin Oncol 1999; 17: 2639-2648.

22. Vogel C, Cobleigh MA, Tripathy D, Gutheil JC, Harris LN, Fehrenbacher L et al. First-line, single-agent Herceptin(R) (trastuzumab) in metastatic breast cancer. a preliminary report. Eur J Cancer 2001; 37: 25-29.

23. Slamon DJ, Leyland-Jones B, Shak S, Fuchs H, Paton V, Bajamonde A et al. Use of chemotherapy plus a monoclonal antibody against HER2 for metastatic breast cancer that overexpresses HER2. N Engl J Med 2001; 344: 783-792. 
24. Geyer CE, Forster J, Lindquist D, Chan S, Romieu CG, Pienkowski T et al. Lapatinib plus capecitabine for HER2-positive advanced breast cancer. N Engl J Med 2006; 355 2733-2743.

25. Verma S, Miles D, Gianni L, Krop IE, Welslau M, Baselga J et al. Trastuzumab emtansine for HER2-positive advanced breast cancer. N Engl J Med 2012; 367: 1783-1791.

26. Baselga J, Cortes J, Kim SB, Im SA, Hegg R, Im YH et al. Pertuzumab plus trastuzumab plus docetaxel for metastatic breast cancer. N Engl J Med 2012; 366: 109-119.

27. Nagata Y, Lan KH, Zhou X, Tan M, Esteva FJ, Sahin AA et al. PTEN activation contributes to tumor inhibition by trastuzumab, and loss of PTEN predicts trastuzumab resistance in patients. Cancer Cell 2004; 6: 117-127.

28. Nahta R, Yuan LX, Du Y, Esteva FJ. Lapatinib induces apoptosis in trastuzumab-resistant breast cancer cells: effects on insulin-like growth factor I signaling. Mol Cancer Ther 2007; 6 : 667-674

29. Berns K, Horlings HM, Hennessy BT, Madiredjo M, Hijmans EM, Beelen K et al. A functional genetic approach identifies the PI3K pathway as a major determinant of trastuzumab resistance in breast cancer. Cancer Cell 2007; 12: 395-402.

30. Eichhorn PJ, Gili M, Scaltriti M, Serra V, Guzman M, Nijkamp W et al. Phosphatidylinositol 3kinase hyperactivation results in lapatinib resistance that is reversed by the mTOR/ phosphatidylinositol 3-kinase inhibitor NVP-BEZ235. Cancer Res 2008; 68: 9221-9230.

31. Esteva FJ, Guo H, Zhang S, Santa-Maria C, Stone S, Lanchbury JS et al. PTEN, PIK3CA, p-AKT, and p-p70S6K status: association with trastuzumab response and survival in patients with HER2-positive metastatic breast cancer. Am J Pathol 2010; 177: 1647-1656.

32. Dave B, Migliaccio I, Gutierrez MC, Wu MF, Chamness GC, Wong $\mathrm{H}$ et al. Loss of phosphatase and tensin homolog or phosphoinositol-3 kinase activation and response to trastuzumab or lapatinib in human epidermal growth factor receptor 2-overexpressing locally advanced breast cancers. J Clin Oncol 2011; 29: 166-173

33. Lang JY, Hsu JL, Meric-Bernstam F, Chang CJ, Wang Q, Bao Y et al. BikDD eliminates breast cancer initiating cells and synergizes with lapatinib for breast cancer treatment. Cancer Cell 2011; 20: 341-356.

34. Valabrega G, Capellero S, Cavalloni G, Zaccarello G, Petrelli A, Migliardi G et al. HER2positive breast cancer cells resistant to trastuzumab and lapatinib lose reliance upon HER2 and are sensitive to the multitargeted kinase inhibitor sorafenib. Breast Cancer Res Treat 2011; 130: 29-40.

35. Moody SE, Schinzel AC, Singh S, Izzo F, Strickland MR, Luo L et al. PRKACA mediates resistance to HER2-targeted therapy in breast cancer cells and restores anti-apoptotic signaling. Oncogene 2014; e-pub ahead of print 9 June 2014; doi:10.1038/onc.2014.153.

36. Liu T, Yacoub R, Taliaferro-Smith LD, Sun SY, Graham TR, Dolan R et al. Combinatorial effects of lapatinib and rapamycin in triple-negative breast cancer cells. Mol Cancer The 2011; 10: 1460-1469.

37. Nowsheen S, Cooper T, Stanley JA, Yang ES. Synthetic lethal interactions between EGFR and PARP inhibition in human triple negative breast cancer cells. PLoS One 2012; 7: e46614.

38. Herschkowitz JI, Simin K, Weigman VJ, Mikaelian I, Usary J, Hu Z et al. Identification of conserved gene expression features between murine mammary carcinoma models and human breast tumors. Genome Biol 2007; 8: R76.

39. Liu R, Zhou Z, Zhao D, Chen C. The induction of KLF5 transcription factor by progesterone contributes to progesterone-induced breast cancer cell proliferation and dedifferentiation. Mol Endocrinol 2011; 25: 1137-1144.

40. Kessler JD, Kahle KT, Sun T, Meerbrey KL, Schlabach MR, Schmitt EM et al. A SUMOylation-dependent transcriptional subprogram is required for Myc-driven tumorigenesis. Science 2012; 335: 348-353.

41. Peppercorn J, Perou CM, Carey LA. Molecular subtypes in breast cancer evaluation and management: divide and conquer. Cancer Invest 2008; 26: 1-10.

42. Chen ZY, Wang X, Zhou Y, Offner G, Tseng CC. Destabilization of Kruppel-like factor 4 protein in response to serum stimulation involves the ubiquitin-proteasome pathway. Cancer Res 2005; 65: 10394-10400.

43. Yoshidome K, Shibata MA, Couldrey C, Korach KS, Green JE. Estrogen promotes mammary tumor development in C3(1)/SV40 large T-antigen transgenic mice: paradoxical loss of estrogen receptor $\alpha$ expression during tumor progression. Cancer Res 2000; 60: 6901-6910.

44. Cory S, Huang DC, Adams JM. The Bcl-2 family: roles in cell survival and oncogenesis. Oncogene 2003; 22: 8590-8607.

45. Milella M, Trisciuoglio D, Bruno T, Ciuffreda L, Mottolese M, Cianciulli A et al. Trastuzumab down-regulates $\mathrm{Bcl}-2$ expression and potentiates apoptosis induction by $\mathrm{Bcl}-2 / \mathrm{Bcl}-\mathrm{XL}$ bispecific antisense oligonucleotides in HER-2 gene-amplified breast cancer cells. Clin Cancer Res 2004; 10: 7747-7756.

46. Dawson SJ, Makretsov N, Blows FM, Driver KE, Provenzano E, Le QJ et al. BCL2 in breast cancer: a favourable prognostic marker across molecular subtypes and independent of adjuvant therapy received. Br J Cancer 2010; 103: 668-675.

47. Huw LY, O'Brien C, Pandita A, Mohan S, Spoerke JM, Lu S et al. Acquired PIK3CA amplification causes resistance to selective phosphoinositide 3-kinase inhibitors in breast cancer. Oncogenesis 2013; 2: e83.
48. Cerami E, Gao J, Dogrusoz U, Gross BE, Sumer SO, Aksoy BA et al. The cBio cance genomics portal: an open platform for exploring multidimensional cancer genomics data. Cancer Discov 2012; 2: 401-404.

49. Gao J, Aksoy BA, Dogrusoz U, Dresdner G, Gross B, Sumer SO et al. Integrative analysis of complex cancer genomics and clinical profiles using the cBioPortal. Sci Signal 2013; 6: I1.

50. Burstein HJ, Sun Y, Dirix LY, Jiang Z, Paridaens R, Tan AR et al. Neratinib, an irreversible ErbB receptor tyrosine kinase inhibitor, in patients with advanced ErbB2-positive breast cancer. J Clin Oncol 2010; 28: 1301-1307.

51. Holzer RG, MacDougall C, Cortright G, Atwood K, Green JE, Jorcyk CL. Development and characterization of a progressive series of mammary adenocarcinoma cell lines derived from the C3(1)/SV40 Large T-antigen transgenic mouse model. Breast Cancer Res Treat 2003 77: $65-76$

52. Beckers J, Herrmann F, Rieger S, Drobyshev AL, Horsch M, Hrabé de Angelis M et al. Identification and validation of novel ERBB2 (HER2, NEU) targets including genes involved in angiogenesis. Int J Cancer 2005; 114: 590-597.

53. Li Z, Zhao J, Li Q, Yang W, Song Q, Li W et al. KLF4 promotes hydrogen-peroxide-induced apoptosis of chronic myeloid leukemia cells involving the bcl-2/bax pathway. Cell Stress Chaperones 2010; 15: 905-912.

54. Mohan N, Ai W, Chakrabarti M, Banik NL, Ray SK. KLF4 overexpression and apigenin treatment down regulated anti-apoptotic Bcl-2 proteins and matrix metalloproteinases to control growth of human malignant neuroblastoma SK-N-DZ and IMR-32 cells. Mol Oncol 2013; 7: 464-474.

55. Chen X, Xu H, Yuan P, Fang F, Huss M, Vega VB et al. Integration of external signaling pathways with the core transcriptional network in embryonic stem cells. Cell 2008; 133 1106-1117.

56. Tiwari N, Meyer-Schaller N, Arnold P, Antoniadis H, Pachkov M, van Nimwegen E et al. Klf4 is a transcriptional regulator of genes critical for EMT, including Jnk1 (Mapk8). PLoS One 2013; 8: e57329.

57. Ilknur GB, Hilmi A, Tulay C, Oguz C, Selma S, Serdar S et al. The importance of extracapsular extension of axillary lymph node metastases in breast cancer. Tumori 2004 90: 107-111.

58. Gruber G, Greiner RH, Hlushchuk R, Aebersold DM, Altermatt HJ, Berclaz G et al. Hypoxiainducible factor 1 alpha in high-risk breast cancer: an independent prognostic parameter? Breast Cancer Res 2004; 6: R191-R198.

59. Wang SL, Li YX, Song YW, Wang WH, Jin J, Liu YP et al. Triple-negative or HER2-positive status predicts higher rates of locoregional recurrence in node-positive breast cancer patients after mastectomy. Int J Radiat Oncol Biol Phys 2011; 80: 1095-1101.

60. Kurebayashi J, Otsuki T, Tang CK, Kurosumi M, Yamamoto S, Tanaka K et al. Isolation and characterization of a new human breast cancer cell line, KPL-4, expressing the Erb B family receptors and interleukin-6. Br J Cancer 1999; 79: 707-717.

61. Elenbaas B, Spirio L, Koerner F, Fleming MD, Zimonjic DB, Donaher JL et al. Human breast cancer cells generated by oncogenic transformation of primary mammary epithelial cells. Genes Dev 2001; 15: 50-65.

62. Morel C, Carlson SM, White FM, Davis RJ. Mcl-1 integrates the opposing actions of signaling pathways that mediate survival and apoptosis. Mol Cell Biol 2009; 29: 3845-3852.

63. Chomczynski P, Sacchi N. Single-step method of RNA isolation by acid guanidinium thiocyanate-phenol-chloroform extraction. Anal Biochem 1987; 162: 156-159.

64. Blanquicett C, Johnson MR, Heslin M, Diasio RB. Housekeeping gene variability in normal and carcinomatous colorectal and liver tissues: applications in pharmacogenomic gene expression studies. Anal Biochem 2002; 303: 209-214.

65. Haibe-Kains B, Schroeder M, Bontempi G, Soririou C, Quackenbush J Genefu: relevant functions for gene expression analysis, especially in breast cancer 2012.

66. Creighton CJ. The molecular profile of luminal B breast cancer. Biologics 2012; 6 : 289-297.

67. Howe EN, Cochrane DR, Cittelly DM, Richer JK. miR-200c targets a NF-kappaB upregulated TrkB/NTF3 autocrine signaling loop to enhance anoikis sensitivity in triple negative breast cancer. PLoS One 2012; 7: e49987.

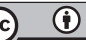

Cell Death and Disease is an open-access journal published by Nature Publishing Group. This work is licensed under a Creative Commons Attribution 4.0 Internationa License. The images or other third party material in this article are included in the article's Creative Commons license, unless indicated otherwise in the credit line; if the material is not included under the Creative Commons license, users will need to obtain permission from the license holder to reproduce the material. To view a copy of this license, visit http://creativecommons.org/licenses/by/4.0/ 